\title{
O “ACONTECIMENTO” COMO PROCEDIMENTO DA VERDADE NA PERSPECTIVA ONTOLÓGICA DE ALAIN BADIOU
}

\section{THE "EVENT" AS PROCEDURE OF THE TRUTH IN THE ONTHOLOGICAL PERSPECTIVE OF ALAIN BADIOU}

\author{
W. R M. ARAÚJO1,*, A. M. O. SIQUEIRA² \\ 1 Doutor em Sociologia pela Universidade Federal do Rio Grande do Sul (UFRGS), Professor da \\ UNINORTE - Laureate International Universities, Manaus, AM. \\ 2 Universidade Federal de Viçosa, Departamento de Química, Brasil
}

\author{
ART ICLE INFO \\ Article history: \\ Received 2018-04-20 \\ Accepted 2018-04-30 \\ Available online 2018-05-30 \\ *Autor correspondente: \\ E-mail:marquesreis@hotmail.com
}

Palavras-chave: Filosofia política. Verdade. Acontecimento. Ontologia.

Keywords: Political Philosophy. Truth. Event. Ontology.

RESUMO. Esta discussão é uma tentativa de delineamento de alguns aspectos básicos da ontologia e da concepção do pensamento político elaborado por Alain Badiou, um filósofo francês contemporâneo, que vem se destacando na construção de uma filosofia política que se propõe a recuperar o ideal emancipatório que, na sua perspectiva, há algum tempo foi abandonado pelos filósofos - em especial os franceses. Inicialmente expõem-se aspectos da trajetória intelectual e do engajamento político do filósofo que, sem sombras de dúvidas, confirmam uma perspectiva políticofilosófico voltada para a práxis. Num segundo momento, procura-se apresentar os conceitos de verdade, acontecimento e a concepção de ontologia do filósofo. Nisso, conclui-se que as questões fundamentais da filosofia de Badiou são ontológicas e não epistemológicas, de fato a investigação badiouano é sobre o ser, a verdade e o sujeito, e não tanto sobre as condições de construção do conhecimento a partir da experiência possível.

ABSTRACT. This discussion is an attempt to delineate some basic aspects of the ontology and conception of political thought elaborated by Alain Badiou, a contemporary French philosopher, who has been emphasizing in the construction of a political philosophy that proposes to recover the emancipatory ideal that, in his perspective, has for some time been abandoned by philosophers - especially the French. Firstly, aspects of the intellectual trajectory and political engagement of the philosopher are exposed, which, without any doubt, confirm a political-philosophical perspective on praxis. In a second moment, we try to present the concepts of truth, event and the conception of ontology of the philosopher. In this, it is concluded that the fundamental questions of Badiou's philosophy are ontological rather than epistemological, in fact the Badiou investigation is about being, truth and subject rather than about the conditions of knowledge construction from the possible experience.

\section{INTRODUÇÃO}

Nascido em Marrocos, o filósofo contemporâneo e romancista francês Alain Badiou foi discípulo de Louis Althusser, cujo pensamento influenciou seus primeiros trabalhos epistemológicos, bem como de Jean-Paul Sartre e também do psicanalista Jacques Lacan, que configuram com sendo seus mestres reconhecidos. Atualmente é Professor emérito do Departamento de Filosofia da École Normale Supérieure, na qual em 2002 fundou o Centre International d'Étude de la Philosophie Française Contemporaine. O radicalismo é considerado uma das principais características que permeiam o ideário desse destacado pensador franco-árabe. No campo da ação política, foi membro- 
fundador do Parti Socialiste Unifié (PSU) e um dos dirigentes da L'Union des Communistes de France Marxiste-Léniniste (UCF-ML), um grupo maoista francês. Em paralelo à carreira acadêmica, engajouse bem cedo numa vigorosa militância política que, atualmente, perdeu intensidade física, cedendo lugar a uma expressiva notoriedade intelectual em razão da reapropriação de seu pensamento para a crítica de questões contemporâneas.

Em Paris, na École Normale Supérieure, onde foi discípulo de Althusser, Alain Badiou estabeleceu uma relação entre política e filosofia que propunha, a princípio, transformar o marxismo de maneira filosófica para influenciar a política do Parti Communiste Français. Nesse sentido, confirma-se que as suas primeiras influências surgem em meio às contestações e aos conflitos dos anos $1960^{1}$, juntamente com Jean-Paul Sartre e, posteriormente, com Louis Althusser, que se dirigiam para um compromisso político vinculado, sobremaneira, a filosofia.

Seguindo uma vertente contrária as tendências filosóficas de matrizes francesas proeminentes durante as últimas três décadas, Alain Badiou preocupa-se com as condições de um pensamento filosófico essencialmente livre. Nisso, ele defenderá que esse modelo filosófico, por consequência, deve caminhar lado a lado de um projeto político emancipatório que, em última instância, seja capaz de criar condições concretas de o pensamento ser, efetivamente, livre - que não seja constrangido por nenhum limite externo, a não ser pelos os limites internos que sua própria lógica Ihe imponha. Tal questão consistirá no ponto central do projeto filosófico emancipatório e, sobretudo político desse filósofo francês contemporâneo. Sua formação filosófica deu-se no cerne dos debates que agitaram a juventude francesa dos anos 50 e 60 do século XX.

Naquele contexto, aconteceram eventos importantes que influenciaram a sua formação político filosófica; o primeiro foi contato que estabeleceu, desde muito jovem, com o pensamento de Jean-Paul Sartre; o segundo, não sem menos importância, foi o início da guerra argelina ocorrida entre os anos de 1954 e 1962. Nestes eventos Badiou constata a relação entre o problema político (a luta anticolonial) e a filosofia. Nesse sentido, segundo ele mesmo pontuou em uma entrevista concedia em 2012 na Universidade Nacional de San Martin, em Buenos Aires, esta relação entre política e filosofia foi estabelecida em sua vida desde muito jovem. Todo o trabalho teórico de Badiou se encontra subordinado exclusivamente à discussão política até 1983, período em que dedicara à militância maoista em prejuízo da crítica à economia política (DIAS, 2011). Após meados dos anos 1980, ele passa a dedicar-se a refundar a filosofia, propondo uma metafísica que, por um lado, está assentada numa identidade entre a ontologia e a matemática e, por outro, numa teoria formal do sujeito que ultrapassam os limites de uma teoria política (DIAS, 2011).

\section{O PROJETO FILOSÓFICO DE ALAIN BADIOU}

$\mathrm{Na}$ consecução de seu projeto filosófico - que aqui categorizamos como "emancipatório" - a questão da "verdade" é desenvolvida em duas obras: i. L'être et l'événement (1988), livro cuja

\footnotetext{
${ }^{1} \mathrm{Na}$ França, os protestos de maio e junho de 1968 (conhecido como "maio de 68") arrastaram para as ruas de Paris multidões de manifestantes que ocuparam universidades, de fato, foi uma grande onda de protestos que teve início com manifestações estudantis para pedir reformas no setor educacional, porém o movimento cresceu evoluindo para uma greve geral de trabalhadores que desestabilizou o governo do então presidente francês, Charles De Gaulle. No entanto, o movimento foi desencorajado pelo Partido Comunista Francês de orientação stalinista, e finalmente suprimida pelo governo, que acusa os comunistas de tramarem contra a República. Segundo Thiollet (1998), "as categorias universitárias, ao lado de outras camadas sociais, mobilizam-se em torno de objetivos políticos, tais como democratização, defesa das liberdades individuais ou coletivas, denúncia contra as guerras etc." (THIOLLENT, 1998, p. 65).
} 
tradução oficial para o português recebeu o título O ser e o evento (1996); ii. Logiques des mondes: l'être et l'événement (2006), traduzido para o português com o título Lógicas dos Mundos: o ser e o evento II (2006). Na primeira, é desenvolvida uma teoria "formal das verdades" que é, ao mesmo tempo, uma teoria do SER onde é proposto que a verdade é, como todas as outras coisas, multiplicidades puras que dependem de um acontecimento (BADIOU, 2015). Desse modo, a verdade sempre dependerá de um acontecimento (a ciência, a arte, a filosofia e o amor) - do mesmo modo que esses acontecimentos são a condição para a filosofia (BADIOU, 1991) -, que provoque uma ruptura.

No entanto, a verdade é uma novidade que não se submete à estrutura da situação; ao contrário, conforme aponta o autor, "tudo isso [acontece] no quadro geral de uma teoria do múltiplo puro, a qual é, de tempos em tempos, afetada por um surgir infundado que eu chamo de acontecimento" (BADIOU, 2015, p. 170). Desse modo, então:

Para que se inicie o processo de uma verdade, é preciso que algo aconteça. Pois, o que existe, a situação do saber tal como está, dá-nos apenas a repetição. Para que uma verdade afirme sua novidade, tem de haver um suplemento, o qual está entregue ao acaso. Ele é imprevisível, incalculável. Situa-se para além daquilo que existe, chamo-o evento (BADIOU, 1994, p. 78).

$\mathrm{Na}$ segunda obra, Alain Badiou retoma a problematização da verdade entrando na questão dos corpos reais, da lógica de suas relações e, em particular, da questão do aparecimento da verdade. Tal discussão comporta uma teoria das relações íntimas que, de acordo com o pensador, são estabelecidas entre a singularidade do mundo e a universalidade de uma verdade; porém o acontecimento se dará em determinadas condições concretas que convergem para a construção do copo das verdades (BADIOU, 2015). Desse modo, a verdade é um corpo subjetivável feito de outros corpos individuais e a tal processo ele nomeará de "incorporação" que, conforme indica, "nos esclarece a maneira pela qual uma verdade é disposta num mundo e a relação que ela tem com os materiais desse mundo, a saber, os corpos e a linguagem" (BADIOU, 2015, p. 172).

Sustento que a verdade é um corpo. Assim, ela é feita do que existe, quer dizer, de outros corpos individuais, e é a isso que se dá o nome de incorporação. Essa incorporação nos esclarece a maneira pela qual uma verdade é disposta num mundo e a relação que ela tem com os materiais desse mundo, a saber, os corpos e a linguagem (BADIOU, 2015, p. 172).

De fato, isso quer dizer que uma verdade é sempre uma multiplicidade unificada ou organizada que torna, sobremaneira, algo compatível sem que necessariamente o fosse. Nesse sentido, ele remete ao campo político contemporâneo - não se restringindo a ele - exemplificado como ocorre o processo unificação da multiplicidade que produz a verdade.

Para dar um exemplo bastante simples: boa parte da concepção daquilo que seria um partido revolucionário consistiria em criar uma teoria em que intelectuais e operários fossem compatíveis, e onde a política tornasse compatíveis as diferenças de classe que em geral não o são. A teoria de Gramsci do intelectual orgânico, e outras teorias próximas, são desse tipo. Elas não tratam simplesmente de diferenças de classe tanto quanto de conflitos, criam também compatibilidades entre classes que não existiam, daí, por exemplo, uma teoria das alianças de classe (BADIOU, 2015, p. 172). 
A questão da verdade é retomada em 1989, no livro Manifeste pour la philosophie, traduzido e publicado no Brasil em 1991 com titulo "Manifesto pela filosofia". Nele, Alain Badiou inicia questionando acerca da possibilidade da filosofia em seu tempo. Nela, o filósofo propõe que a base do pensamento ocidental encontra-se na antiga Grécia, portanto, recupera a tradição filosófica platônica para reivindicar que a filosofia contemporânea deva "dar um passo a mais".

Afirmo não somente que a filosofia é hoje possível, mas também que essa possibilidade não tem a forma da travessia de um fim. Trata-se, muito pelo contrário, de saber o que quer dizer: dar um passo a mais. Um só passo. Um passo na configuração moderna, essa que, depois de Descartes, ligo às condições da filosofia os três conceitos sociais nodais que são, o ser, a verdade e o sujeito (BADIOU, 1991, p. 5).

Nesse sentido, as questões fundamentais da filosofia são ontológicas e não epistemológicas, e o inquérito badiouano, como citamos acima, é sobre o ser, a verdade e o sujeito, e não tanto sobre as condições de construção do conhecimento a partir da experiência possível (DIAS, 2011). Tais conceitos são apontados como os mais criticados e desconstruídos pelos filósofos contemporâneos, dentre estes, o conceito que se presta, infalivelmente, à produção filosófica contemporânea é o de verdade (BADIOU, 1991). Mas ele considera que a filosofia é incapaz de produzir verdades a partir de suas próprias forças reflexivas, pois essa não é uma forma cultural necessária.

A filosofia pronuncia, não a verdade, mas a conjuntura, quer dizer, a conjunção pensável das verdades. Uma vez que a filosofia é um exercício de pensamento sobre a brecha do tempo, uma torsão reflexiva sobre o que a condiciona, ela se sustenta, o mais frequente, em condições precárias, nascentes. Ela se institui na abordagem da nomeação pela qual um evento [acontecimento] engata num procedimento genérico. O que condiciona uma grande filosofia, muito para além dos saberes instituídos e consolidados, são as crises, as irrupções e paradoxos da matemática, os terremotos da língua poética, as revoluções e provocações da política inventada, a vacilação das transações dos dois sexos (BADIOU, 1991, p. 11-12).

$\mathrm{Na}$ verdade, a filosofia tem por tarefa tramar as verdades produzidas em cada uma de suas quatro condições (a arte, o amor, a política e a ciência) reunindo, desse modo, as nomeações decorrentes do conhecimento, na melhor das acepções desse filósofo. Nestes termos, é preciso que haja um "acontecimento" que provoque uma ruptura no estado da "situação" - definida como "um estado de coisas, um múltiplo apresentado qualquer" (BADIOU, 1991, p. 10) - e também nos "regimes de verdades" que conformam nossa cotidianidade e a produção de conhecimento (BADIOU, 1991).

Nesse sentido, Badiou tem se destacando pela construção de um projeto filosófico original que busca recuperar o ideal emancipatório abandonados já há algum tempo pelos filósofos (em especial os franceses) que trazia por nome a palavra comunismo. Tal projeto emancipatório pode ser sintetizado na seguinte proposição - adotando as palavras do pensador - como: "Todo o meu trabalho filosófico consiste em propor uma nova definição do que é uma verdade e em tirar conclusões disso em relação à nossa existência como sujeitos" (BADIOU, 2015, p. 70).

Tal noção de verdade está vinculada, de fato, a um acontecimento concreto que, sobretudo, rompe com o estado da situação (metaestrutura); "verdade que não é saber e conhecimento (repetição de informações sobre um status quo), mas ruptura e novidade que cria subjetividade" 
(LIMA, 2013, p. 11). Nisso, um dos princípios de sua filosofia consiste em dizer que uma vida que não está regida pelo signo da "ideia" (que o é intermediário entre as "verdades universais" e o indivíduo) não é uma vida verdadeira.

Alain Badiou enxerga de forma bastante lúcida qual é o problema contemporâneo da filosofia: a reinvenção da "verdade", da ideia de verdade descartada pela filosofia francesa como algo intrínseco (e talvez ontologicamente) totalitário. Do mesmo modo, esse filósofo original tem se dedicando desde o inicio de sua trajetória intelectual à crítica aguda das democracias liberais contemporâneas e, sobretudo, dos "direitos humanos" que, para ele, são ferramentas ideológicas que sustentam o capitalismo em suas atuais configurações.

No campo da filosofia política, ele é conhecido por sua crítica radical as democracias liberais e aos direitos humanos que, para ele, fariam parte do fundamento ideológico sustentador do capitalismo em suas configurações atuais. Nesse sentido, Alain Badiou firmou-se como referência importante nos debates sobre a renovação do pensamento de esquerda. Assim, desde cedo, ele compreendeu que a política não poderia ser guiada por exigência de realização de ideais normativos de justiça e consenso que já estariam presentes em alguma dimensão da vida social. $\mathrm{Na}$ compreensão dos acontecimentos 1968 ocorridos na França, Alain Badiou considera também relevante a análise dos eventos que irrompem os anos anteriores como a guerra da Argélia e, precipuamente, a marcha dos argelinos em Paris ocorrida em outubro de 1961, e organizada pela "Frente de Libertação Nacional" argelina. Naquele período centenas de civis argelinos foram perseguidos e mortos pela polícia francesa.

Na entrevista Alain Badiou: El Militante Fiel, concedida em 2012 ao Lectura Mundi, programa² de debates realizados na Biblioteca Central de la Univesidad Nacional de San Martín (UNSAM), Alain Badiou retoma questões relativas à sua formação intelectual influenciada por Jean Paul Sartre e Luis Althusser, ambos filósofos franceses contemporâneos, bem como traça os principais acontecimentos políticos que influenciaram seus posicionamentos intelectuais e políticos,

De acordo com Alain Badiou (2012), os anos 1960 foi um período que se assistiu à ação da polícia francesa na sua forma mais violenta. Eventos os quais o filósofo se engaja apaixonadamente. Naquele período, ele torna-se "uma espécie de rebelde, de militante" e, como ele mesmo afirma, "foi um período em que participei da política na sua forma mais violenta". Naquele contexto conturbadas manifestações estudantis, onde irrompia na capital francesa o "Maio de 68", ele foi nomeado professor deu cidade da região de Provence, localizada no sudoeste da França.

Tais episódios corroboraram para que ocorresse uma mudança radical em sua vida de militante, em suas concepções e em sua filosofia, sobretudo, por duas razões: "a primeira é que participava pela primeira vez de um acontecimento positivo. Havia um vínculo que se estabelecia entre os militantes populares e os militantes operários; e havia ideias de libertação, de emancipação que se discutiam em toda a França" (BADIOU, 2012), conforme dissera em entrevista. Esse acontecimento na percepção de Badiou, que segue dizendo, "não era como a luta contra a guerra da Argélia que era uma resistência difícil e negativa".

\footnotetext{
${ }^{2}$ O programa edita a Revista Anfíbia, publicação digital dedicada a relatos de não ficção e crônica destaque significativo no cenário latino-americano, o programa propõe-se a partir de uma plataforma de pesquisa permanente, que inclui intercâmbios, seminários, workshops e conferências, discussões e debates sobre uma variedade de questões contemporâneas, refletindo sobre o papel da Universidad Nacional de San Martín frente aos desafios teóricos, políticos e sociais contemporâneos.
} 
Nesse caso, ao contrário dos acontecimentos precedentes, era como um nascimento e, como ele mesmo pontua: "como algo que surgia, era um pouco como uma primavera da vida e da ação". Nisso, ele constata, portanto, que o que realmente muda a vida das pessoas é quando se produz algo afirmativo, isto é, um acontecimento que efetivamente propõe algo novo. A segunda razão, conforme afirma Alain Badiou: "é que me dei conta de que tudo isto tinha também uma ressonância mundial [...]. Então intentei, filosoficamente, pensar a relação entre a ação local (Maio de 68) parisiense e francesa e os grandes processos históricos no cenário mundial". Isso quer dizer que Alain Badiou constatou que se produzia naquele mesmo momento a Revolução Cultural na China, o movimento da juventude na Alemanha e Estados Unidos e a Guerra do Vietnã, dentre outros. Ele se dera conta de "que a filosofia é também um meio para pensar ao mesmo tempo o que está à vista, o que se experimenta".

Nesse sentido, tal constatação leva Alain Badiou a pensar os acontecimentos de forma original tanto em escala maior possível (internacionalismo) como, também, a relação muito estreita nesses acontecimentos entre pessoas diferentes (trabalhadores, estudantes, intelectuais), buscando compreender o vínculo político real entre intelectuais e operários. Isso nos leva a inferir que, a partir desses eventos, Alain Badiou estabelece uma nova relação entre filosofia e política que o acompanharão em toda a sua trajetória intelectual e política.

\section{O ACONTECIMENTO ENQUANTO RUPTURA COM A METAESTRUTURA}

A noção de acontecimento é produzida por Badiou na obra, publicada em 1988, intitulada precisamente $O$ ser e os eventos. Neste caso, especificamente, a noção de acontecimento ( $\mathrm{re}$ ) introduziu, no auge do neoliberalismo, ideias subversivas, tais como a importância do acaso, o papel ativo do sujeito e a importância das pausas. Conforme Madarasz (2011), de Deleuze a Derrida, o sentido que se tem atribuído ao conceito de "acontecimento" tornou-se, de fato, uma das principais questões a ser tratada em relação ao conceito de diferença radical, exame este que Badiou buscou empreender como projeto filosófico. Nesse sentido, Badiou "introduz um conceito que possibilita a ruptura da repetição dos privilégios do estado da situação (ou metaestrutura): o acontecimento, que é a novidade radical capaz de atravessar a lógica cristalizada a fim de afirmar-se enquanto novidade" (CAMAROTTI, 2011, p. 84).

De acordo com Camarotti (2011) - seguindo a perspectiva do filósofo -, o acontecimento ${ }^{3}$ tem lugar de tempos em tempos, ocorrendo de maneira aleatória, de forma absolutamente imprevisível e, sobremaneira, impredicável do ponto de vista do saber substancial da situação, por isso mesmo, subvertendo os critérios estabelecidos. Para Badiou (1996), todo grande acontecimento é (de certa forma) um encontro, e sua principal característica é a ruptura do status quo intrínseco à metaestrutura. É o encontro de uma relação, de um vínculo, de uma realidade que não conhecemos e com a qual propomos algo novo; é o acontecimento que coloca a possibilidade da irrupção do novo. Assim, "o acontecimento é o mais intensivo das quatro figuras de mudança que emergem numa

\footnotetext{
${ }^{3} \mathrm{Na}$ obra $\mathrm{O}$ ser e o evento, o tradutor nacional optou por "evento", para o vocábulo "événement", contudo, em outras traduções para o português o termo foi traduzido por "acontecimento". O ser e o acontecimento foi publicada em 2006 e se chama Lógicas dos mundos. Nesta discussão usaremos, para todos os fins, a segunda opção, por crermos ser mais bem adaptada à palavra estrangeira.
} 
filosofia do aparecer de mundos. A origem de um mundo agora se localiza num ponto de inexistência" (MADARASZ, 2011, p. 98).

O acontecimento, portanto, inaugura aquilo que Badiou chama um "procedimento de verdade", uma vez que, ao contrário de uma concepção clássica da verdade como adequação entre fato e representação. Badiou entende a verdade como sendo sempre ruptura numa dada situação, sempre portadora de uma radical novidade em relação ao que existia. Nestes termos, o encontro é uma espécie de "dom", um tipo de graça, ou seja, é algo imprevisível, incalculável e absolutamente necessário. Entretanto, observa o autor, mais importante do que o encontro, são suas consequências e, principalmente, o que vai realmente mudar as coisas e as concepções.Ele quer dizer que isso significa aceitar o encontro e tomar as consequências, comprometendo-se com a construção da vida que dependa justamente desse encontro. Em síntese, "o acontecimento é, então, a apresentação da verdade da situação (nos termos da oportunidade de aparecimento do novo); assim como é aquilo que, negativamente, explicita os interesses que compõem a lógica da dominação" (BADIOU, 1996).

Não podemos deixar de demarcar que o do ponto de vista da abordagem badiouano, um "acontecimento" não tem existência durável. Uma vez que a sua sustentação é puramente subjetiva, assim como a sua condição mesma não pode ser provada com base no saber da situação, cabendo apenas sua afirmação por um sujeito fiel. Conforme Camarotti (2011, p. 88): "esta afirmação liga-se à intervenção, que é precisamente $\mathrm{o}$ ato de nomear, contra aquilo que cristaliza uma situação, o acontecimento". De modo que,

A compreensão e a definição de "acontecimento" também atravessam uma mudança importante no sistema, na medida em que Badiou passa do registro ontológico ao do aparecer num mundo. $\mathrm{Na}$ ontologia, o acontecimento é definido de maneira subtrativa como ruptura na situação, o mais verdadeiro conjunto de mudança; é o sítio de um acontecimento que Ihe dá seu caráter. Em Logiques des mondes, o acontecimento é o mais intensivo das quatro figuras de mudança que emergem numa filosofia do aparecer de mundos. A origem de um mundo agora se localiza num ponto de inexistência (MADARASZ, 2011, p. 97-98).

Nessa direção, longe de ser uma opção ou uma escolha, o acontecimento é antes a confirmação de um "chamado" que apenas faz sentido para o sujeito que o identifica nos interstícios de um contexto normalizado. Desse modo, o acontecimento é um colapso da fundação, uma desestabilização da substância "metaestruturante" a partir de onde "o vazio de uma situação é retroativamente detectável" (BADIOU, 1996, p. 53). Assim, a nominação de um acontecimento é, na acepção de Badiou, episódios de um dado contexto que podem, na melhor das circunstâncias, suscitar no sujeito novas formas de subjetividade, onde o acontecimento é uma ruptura por meio da qual se manifesta o não ser (BADIOU, 1996). De modo que, segundo a perspectiva de filósofo, não existe mundo sem acontecimento:

A relação do sujeito com a ordem do mundo, a existir, tem de ser uma relação pensada fora do quadro da necessidade, já que, para Badiou, a existência de todo e qualquer sujeito está dependente da ocorrência, puramente contingente, de um acontecimento imprevisível, de uma irrupção intempestiva (no sentido de que o acontecimento ocorre sempre num tempo que está fora dos seus eixos, que não pode ser integrado no tempo contínuo, mensurável, sequencial e acumulativo, que é o tempo humano 
sob o capitalismo ) na ordem repetitiva da existência [...]. O acontecimento inaugura aquilo a que Alain Badiou chama um "procedimento de verdade", uma vez que, ao contrário de uma concepção clássica da verdade como adequação entre facto e representação (linguística, visual, etc.), Badiou entende a verdade como sendo sempre ruptura numa dada situação, sempre portadora de uma radical novidade em relação ao que existia (DIAS, 2011, p. 22-23).

À vista disso, além de apontar o acontecimento como possibilidade de mudança do status quo, Badiou (1996) acentua as quatro dimensões (esferas da vida) possíveis para o acontecimento: o amor, a arte, a ciência e a política. Nisso, ele define os domínios característicos de cada dimensão: o amor é da ordem dos indivíduos, pois apenas para esse a declaração de um encontro tem lugar (e subverte profundamente toda uma vida - e que, no íntimo dessa subversão, funda as subjetividades); a arte e a ciência são igualmente originadas na ordem do indivíduo, porém seu interesse é coletivo, ao contrário do amor (seriam, então, dimensões "mistas"); a política, por sua vez, é da ordem do coletivo, portanto o seu interesse é também coletivo.

\section{A CONCEPÇÃO DE ONTOLOGIA NA PROPOSTA DE ALAIN BADIOU}

Metodologicamente, para compreender as implicações práticas da ontologia e da ética em Alain Badiou, é preciso dedicar atenção especial à sua composição política. Isto é, à sua leitura dos processos genéricos de acontecimentos do verdadeiro no âmbito político oferecem as chaves de compreensão da ontologia proposta. Badiou parte, primeiro, da compreensão que a ontologia é a descrição do SER enquanto multiplicidade sem unidade e, em um segundo momento, da forma como as multiplicidades surgem agregadas à outras multiplicidades, onde os objetos não são mais do que um agregado múltiplos. $\mathrm{Na}$ acepção desse pensador contemporâneo, ontologia e ética se relacionam de forma a recompor com as possibilidades subjetivas de ruptura de situações "totalitárias". Nisso ele aponta que: "na ética, o sujeito se apresenta ele mesmo, decide ele mesmo, declara o que ele quer em seu próprio nome" (BADIOU, 1999, p. 42).

Nesse sentido, deve se atentar as situações "aquelas em que ocorre uma totalização simbólica (metaestrutural, em seu vocabulário) a partir dos interesses de uma parte específica, excluindo, assim, aquilo que não reverencia a lógica dominante de sentido" (CAMAROTTI, 2011, p. 102). Isso quer dizer que, a totalização simbólica é coordenada pelo Estado ocorrendo, portanto, no âmbito da política estatal, desse modo, contemplando os interesses de uma minoria com se fossem de uma totalidade.

A política não pode ser guiada por exigência de realização de ideais normativos de justiça e consenso (através da construção de tecnologias de inclusão) que já estariam presentes em alguma dimensão da vida social (BADIOU, 1999). É desse modo porque tais ideais normativos impedem, efetivamente, desenvolvimento de uma crítica mais profunda que permita questionar a gênese de nossos próprios ideais de justiça e consenso.

Desse modo, Badiou se coloca contra a ontologia hermenêutica de orientação heideggeriana (e contra a generalidade das teorias ligadas a qualquer espécie de viragem linguística), e formula uma ontologia subtrativa cuja possibilidade de verdade depende não de um desvelar na pluralidade da linguagem; mas como sendo sempre ruptura de uma situação. Nesse sentido, Badiou (1999) busca defender os avanços na teorização das situações mundanas a partir de uma perspectiva prioritariamente formal e, sobretudo, desprovida da persecução/problematização de significados 
partindo da tradição da racionalidade analítica. Nisso, o filósofo toma a ontologia por caminho e método. Desse modo, aponta que a matemática (les mathematiques) é a ciência do ser-enquanto-ser, a ontologia - daí a equação matemática = ontologia

A identidade entre matemática e ontologia é uma proposta que resulta de uma decisão filosófica essencial, a que postula o ser como pura multiplicidade inconsistente, sem qualquer determinação predicativa e, acima de tudo, sem qualquer resolução numa figura de unidade. Essa proposta, sobre a qual assenta o edifício teórico badiouano, não é, na linguagem adotada por Badiou em EE [O ser e acontecimento], uma proposta ontológica, porque não diz respeito aquilo que o ser é, mas sim à linguagem na qual ele pode ser dito (DIAS, 2011, p. 35).

$\mathrm{Na}$ verdade, só haveria o que saber do ser o seja matematicamente pronunciável. Nessa direção de entendimento, ele identifica a ontologia com a matemática, portanto, sendo desta ordem, o domínio do ser enquanto ser é o da multiplicidade irredutível ao UM/UNO. Noutras palavras, significa que a ontologia badiouano assenta no princípio da multiplicidade do ser, ou seja, na recusa de qualquer interpretação do ser sob a figura do UM, quer essa unidade seja uma entidade transcendente, a natureza ou o universo.

Temos, portanto duas ontologias, ou duas regiões do inquérito ontológico: uma subordinada às multiplicidades puras, entendidas fora de qualquer determinação, que é a ontologia como ciência do ser-enquanto-ser "être-entant-qu'être", e outra que dá conta do ser tal como ele aparece. No primeiro caso a ontologia é um discurso das multiplicidades inconsistentes (sem qualquer princípio de unidade), enquanto que no segundo se trata do que Badiou chama multiplicidades consistentes: - tudo o que é, é multiplicidade inconsistente, mas não aparece num mundo ou numa situação senão como multiplicidade consistente, como uma unidade. No primeiro caso, temos a coisa, no segundo o objeto (DIAS, 2011, p. 24).

As coisas e objetos compõem a totalidade do que é do que é (a ordem do ser) e do que existe (a ordem do parecer), porém não totaliza nem o ser nem a existência. Desse modo, a ontologia badiouana é, de fato, "a descrição do ser enquanto multiplicidade sem unidade, e, num segundo momento, do modo como essas multiplicidades aparecem agregadas noutras tantas multiplicidades: os objetos não são mais do que múltiplos de múltiplos" (DIAS, 2011, p. 12). Tal pressuposto denota a critica badiouana a metafísica dogmática de Heidegger, por esse eleger os meios errados para criticála, de fato, "o que está em questão, para Badiou, é a formalização do ser das situações que não pode mais ser descrito nos termos poéticos de Heidegger, com sua 'morada na linguagem', mas unicamente a partir de uma apresentação algébrica" (CAMAROTTI, 2001, p. 79).

Nessa direção, ele aponta que a apreensão do "ser" pela via da compreensão em última análise não passaria de uma doação de sentido(s) ao ser, uma espécie de substancialização daquilo que em si mesmo não realiza a poesia fluida ou o circuito hermenêutico da linguagem, fazendo assim com que o ser desapareça logo ali na Lichtung (clareira) onde se pensou desvelá-lo. Em síntese, ele assume uma posição radicalmente antitética à "verdade como verdade do ser", uma vez que para ele a ocorrência da verdade depende do acontecimento, uma ruptura da "ordem do Ser", da regularidade errante do "deixar ser" do ser. A ontologia de Badiou é extensiva por não tem a pretensão de entender a realidade. 
Trata-se de uma ontologia para entender o "ser" a partir da teoria dos conjuntos, pois, segundo ele, a filosofia não tem muito a dizer sobre o "ser". Assim sendo, conceito mais relevante à produção filosófica, segundo Badiou, é o de verdade. Entretanto, afirma que a filosofia, com suas próprias forças, não é capaz de produzir verdades. Isso porque, para ele, a filosofia não é uma forma cultural necessária; para que haja filosofia, é preciso a existência anterior de um acontecimento (BADIOU, 1991).

A tese fundamental pela coerência do seu sistema é a de que a ontologia é a matemática, ou seja, a ciência do ser enquanto ser é a mesma ciência que a do múltiplo enquanto múltiplo. Sendo assim, a verdadeira ontologia que possibilita a mudança é a inconsistência. Na verdade, para Badiou (1991), é na inconsistência do uno que se mostra a inconsistência do múltiplo (o que têm todos os conjuntos em comum é o vazio), ou seja, se o "ser" é inconsistente (o uno inexiste fora da multiplicidade), todas as situações são múltiplas frente à impossibilidade de uma totalidade.

Nesse sentido, é partindo desta perspectiva que Badiou afirmará que o acontecimento (evento) ocorrerá dentro e a partir da singularidade. Desse modo, então, ele afirmará que há uma multiplicidade pura dentro do vazio, por isso o acontecimento (evento) ocorrerá dentro da singularidade. Entretanto, segundo o filósofo, essa multiplicidade que inexiste é capaz de produzir um acontecimento (evento) histórico. Nisso são três os exemplos de multiplicidade: o cidadão, a burguesia e a excrescência.

Em linhas rápidas, explicando a partir de Badiou, como o uno não existe fora da multiplicidade, a igualdade seria algo escandaloso, por isso ele não acredita em cidadania e democracia (enquanto forma final de uma sociabilidade), portanto, o cidadão não existe. Todas essas categorias são resultado da metaestrutura. No seu entendimento, o Estado está sempre buscando formas de incluir tudo dentro da metaestrutura, ou seja, o social é resultado da constante construção de tecnologias de construção por parte do aparelho estatal. Todas as suas tecnologias participativas são formas de incluir, excluir e manter as singularidades (negros, indocumentados, sem-teto, homossexuais, indígenas, migrantes, entre outras). Nesse caso, os indocumentados, por exemplo, são incluídos pelo Estado através da não documentabilidade, por este aspecto, tornam-se uma excrescência e, ao mesmo tempo, uma singularidade dentro da multiplicidade.

À vista disso, a excrescência é, para Badiou, uma forma de metalinguagem utilizada pelo Estado para controlar e ordenar a desordem. Noutras palavras, pode-se dizer que o Estado cria novas categorias e novas cidadanias, a partir um jogo de categorização que leva a uma multiplicidade de diferentes categorias e a novas formas de cidadania, através do critério de inclusão/pertencimento. Entretanto, passam a existir multiplicidades dentro dos múltiplos, que vão construindo vazios pela impossibilidade de conciliar inclusão e pertencimento.

\section{CONCLUSÃO}

No fundo, o projeto filosófico de Badiou questiona a metafísica clássica escapando do jargão contemporâneo que busca aniquilar a "verdade" enquanto categoria prática e teórica. Nesse sentido, as questões fundamentais da filosofia Badiou são ontológicas e não epistemológicas, de fato a investigação badiouano é sobre o ser, a verdade e o sujeito, e não tanto sobre as condições de construção do conhecimento a partir da experiência possível. No que diz respeito à sua militância política, verifica-se que ele tem se dedicando, desde o início de sua trajetória intelectual à crítica 
aguda das democracias liberais contemporâneas e, sobretudo, dos "direitos humanos" as quais, para ele, são ferramentas ideológicas que sustentam o capitalismo em suas atuais configurações.

Tal aspecto indica que esse filósofo francês compreendeu muito bem que a política não pode ser guiada por exigência de realização de ideais normativos, sobretudo, os de justiça e consenso que já estariam presentes em alguma dimensão da vida social. Mas foi, precisamente, após meados da década de 1980 que ele empreende num projeto intelectual para além da filosofia política com alcances mais amplos abrangendo uma proposta ontológica. Isto quer dizer que, de acordo com a sua filosofia política, toda conformação histórico-social é determinada segundo critérios de pertença e também de não pertença, e que estes critérios são motivados na/pela parte dominante. Na melhor de suas definições, um acontecimento é, portanto, uma excrescência sobre o estado da situação (status quo), porém, visto pela ontologia, ele é sempre e especificamente localizado no âmbito delimitado de uma das condições, da arte, da ciência, da política de emancipação ou do amor.

Não tivemos a pretensão de aprofundar a problematização teórica de Badiou, a princípio, intentamos recuperar e delinear conceitos relevantes para o início de diálogo com esse filósofo francês que, de início, demonstra sua pertinência para a leitura das irrupções sociais que inauguraram os fins da primeira e início da segunda década do século XXI. Tomando como referência esse pensador francês, afirmamos que a "inconsistência" é o fundamento da realidade que permite a ilusão do acontecimento. Mais ainda, a inconsistência permite, ainda, a irrupção de uma realidade, da ordem das coisas e do status quo que instituem os regimes de verdades. A leitura da trajetória política e intelectual desse pensador confirma que a sua leitura das irrupções (acontecimentos) políticas da década de 1960 (e também dos anos que antecederam) corroboraram para que ocorresse uma mudança radical em sua vida de militante, em suas concepções e em sua filosofia.

Desse modo, "o momento em que a filosofia intersecta as políticas reais é, para Badiou, uma condição de existência da própria filosofia, e isso se aplica à sua própria teoria da política" (DIAS, 2011, p.10). A despeito de filosofia e política constituírem, em sua definição, dois modos de pensamento próprios que embora estabeleçam certas aproximações, de modo algum, seguem trajetórias paralelas. No Brasil, as manifestações que irromperam em diferentes capitais brasileiras a partir meados de 2013 , inicialmente motivadas por uma pauta única (os aumentos das passagens do transporte público), que se estenderam pelos anos seguintes motivadas por diferentes reivindicações foram, de fato, resultado da inconsistência da ideia de inclusão de grupos de minorias sociais subrepresentadas que não são (ou não se sentem) incluídos dentro de projetos de cidadania. Tais irrupções, na melhor das acepções de compreensão traduzem, de fato, aquilo que aqui problematizamos, isto é, assistiu-se a um acontecimento que visou à mudança do "estado da situação".

\section{REFERÊNCIAS}

BADIOU, Alain. Verdade e sujeito. In. Revista Estudos Avançados. Tradução de Jean Briant. n. 8 (21), 1994, p. 177- 184.

Conferências de Alain Badiou no Brasil. Trad. e organização Célio Garcia. Belo Horizonte: Autêntica, 1999.

O ser e o evento. Rio de Janeiro: Jorge Zahar, 1996. 
Manifesto pela filosofia. Revisão da tradução: Aluisio Menezes e PMSJr. Rio de Janeiro: Aoutra Editora, 1991. (Psicanálise \& Cia)

Verdade e sujeito. Estudos Avançados 8 (21), 1994. Disponível em: <http://www.scielo.br/pdf/ea/v8n21/11.pdf>. Acessado em: 25 de set. 2016.

. Logiques des mondes: l'être et l'événement 2. Paris: Seuil, 2006.

. Por uma nova definição da verdade. Tradução Luiz Paulo leitão Martins In: Revista ágora (Rio de Janeiro) v. XVIII n. 2 jul/dez 2015, p. 169-180.

CAMAROTTI, Lucas. Verdades sem significado: ontologia, ética e política em Alain Badiou. In: Cadernos de Ética e Filosofia Política 19, 2/2011, p.77-104.

DIAS, Bruno, M. F. P. Acontecimento, verdade e sujeito: a política como condição da Filosofia em Alain Badiou. Dissertação de Mestrado. Universidade de Lisboa. Faculdade de Letras / Departamento de Filosofia. Lisboa: Portugal, 2011.

GAGO, Verónica. Entrevista a Alain Badiou: "El Militante Fiel". (Alain Badiou em la Universidad Nacional de San Martín/ Buenos Aires, 2012). Disponível em: http://www.youtube.com/watch?v=Mjl9QLWElgU . >. Acessado em: 25 de set. 2016.

LIMA, Francisco, J. G. de. Filosofia, verdade e política em Alain Badiou. In: Griot - Revista de Filosofia v.8, n.2, dezembro/2013, p. 1-13.

MADARASZ, N. R. A superação da Ontologia Fundamental de Heidegger pela Filosofia em Sistema de Alain Badiou. In: Ensaios Filosóficos, Volume IV - outubro/2011. Disponível em: < http://www.ensaiosfilosoficos.com.br/Artigos/Artigo4/MADARASZ Norman Roland.pdf>.

Acessado em: 20 de abr. 2018.

. O Múltiplo sem um. Uma apresentação do Sistema de Alain Badiou. 216. ed. São Paulo: Ideias e Letras, 2011.

O Realismo Estruturalista: do intrínseco, do imanente, do inato. 1. ed. Porto Alegre: Editora Fi - Série Filosofia e interdisciplinaridade, 2016. v. 1. 461.

THIOLLENT, Michel. Maio de 1968 em Paris: testemunho de um estudante. Tempo Social; Rev. Sociol. USP: São Paulo, 10(2): 63-100, out. de 1998. 